\title{
THE LEPROTIC CHILD IN AFRICA
}

JAmEs Ross InNES, M.D., D.T.M.

(A paper read at the Conference on the African Child, held at Nairobi, Januar) 1953, under the auspices of the Standing Committee for Medical Research in East Africa and published by permission.)

\section{INTRODUCTION.}

Leprosy surveys carried out by the author from I946 to I951 in East Africa, of which the main findings have been reported elsewhere (Ref. I to I2), give much data for the study of the child sufferer from leprosy. From records of these surveys it is proposed to make a study of epidemiological naturc of 1,492 cases of child leprosy which were found in the natural or untreated state amongst a total of 7,072 cases of leprosy of all ages.

For the purpose of this paper, the term " child " will be taken to include all persons of I4 years of age and under.

The countries in which these $\mathrm{r}, 492$ child cases were found comprise Kenya, Tanganyika, Zanzibar and Pemba, Uganda, Northern Rhodesia and Nyasaland. Nearly every African tribe resident in these countries is represented amongst these leprotic children. It must be understood that the body of child cases dealt with is non-institutional in origin, and that they do not come from existing leprosaria. They come from the homes and villages of the people, and at the time of discovery were living in the same conditions as their non-leprotic brethren.

It is not proposed to make an exhaustive study. The main object of this paper is to present a picture of the African child in relation to leprosy, and to show that the African child is at the very heart of the leprosy problem in these parts of Africa.

\section{SECTION 1. The child case rate.}

These I,492 children occurred as part of a total of 7,072 cases of leprosy of all ages, which emerges as a child rate of 21 per cent.

This figure represents the averages for a very wide area, but confirmation deriving from other work of local scope comes from the survey of WheATE (I95I) Ref. I3, in the Teso District of Uganda, where he encountered a child rate of 22.5 per cent.

The significance of a child leprosy rate of over 20 per cent. hardly needs pressing. The disease of leprosy must be a living and continuing entity amongst the people. To put it another way, if not a single case of child leprosy had been found, one would have been looking confidently to the disease being about to die out. 
SECTION 2. The sex incidence.

Lowr: ( I934) Ref. I4, made a valuable review of the literature on the sex incidence of leprosy, and came to the conclusion that the number of males is to females as 2 to $\mathrm{I}$.

As regards children, Cochrane (I947) Ref. I5, states that in Saidapet in Madras, male children were to females as 77 to 68 , and considers that in child leprosy the disparity between the sexes is lost. This is not quite borne out by our present study, for of the I,492 children, males were 867 and females 625 , which is a male preponderance of roughly 4 to 3 .

The male preponderance seems therefore mildly to persist, even in child leprosy.

The full explanation of the difference in the sex incidence of leprosy is not yet available. De Souza Campos and De Souza Lima ( 1950) Ref. I6, in their monograph “ Lepra na Infancia " mention the action of the sex hormones as one of the possible explanations for the accepted sex differentiation of 2 to I, and they also found a lesser disproportion among children, namely 52 per cent. of males and 48 per cent. of females; they believe that this slighter difference is based on " the sexual neutrality " of childhood.

This explanation based on the greater vital force of females in resisting the acquisition of leprosy is at least plausible. To this the author would add that he has observed in his surveys that girls were usually cleaner than boys. Poor personal and clothes cleanliness might very well play a part in the acquisition of a disease which makes a certain part of its attack via the skin.

\section{SeCtion 3. Age incidence.}

Of the I,492 cases, ages in years were as folows . . .

$\begin{array}{cccccccccccccc}\text { ages } & \text { I } 4 & \text { 13 } & \text { I } 2 & \text { I I } & \text { I0 } & 9 & 8 & 7 & 6 & 5 & 4 & 3 & 2 \\ \text { number } & 210 & \text { I92 } & \text { 170 } & \text { I } 89 & 201 & \text { 154 } & \text { I60 } & \text { I06 } & 64 & 25 & \text { I5 } & 5 & \text { I }\end{array}$

These figures, presented in the form of a graph, q.v., show a very marked inrush of cases between the ages of 5 and 14 years. In this respect, it is interesting to note the finding of Lowe (I938) Ref. I7, from Bengal, where he says that "the years between 3 and 30 are the most likely for the signs of the disease to appear, and that the maximum appears to be between 5 and I5."

It must be noted that there is a latent period in leprosy of 2 to 5 years' duration, existing between the point where the disease was first acquired and the first presentation of the detectable signs of the disease. Following out this thought, it will be seen that it is a fair deduction that the one child case in particular who was 2 years of age when seen, and who rather astonishingly was a female and a lepromatous case, might well have sustained the infection at birth, 
and that a considerable proportion of the cases must have sustained their infections at a very tender age.

There is general agreement now that by an overwhelming preponderance, leprosy is sustained in childhood and youth. CocHRANB ( I947) Ref. I8, goes so far as to say that " leprosy cannot be maintained in the community in the absence of child infection," and most agree with this. If we insure that children are removed from all contact with infectious leprosy cases, we can lay the foundation for a complete abolition of the disease. We have ever to think of leprosy as a problem based in the environment and living conditions of children and the young.

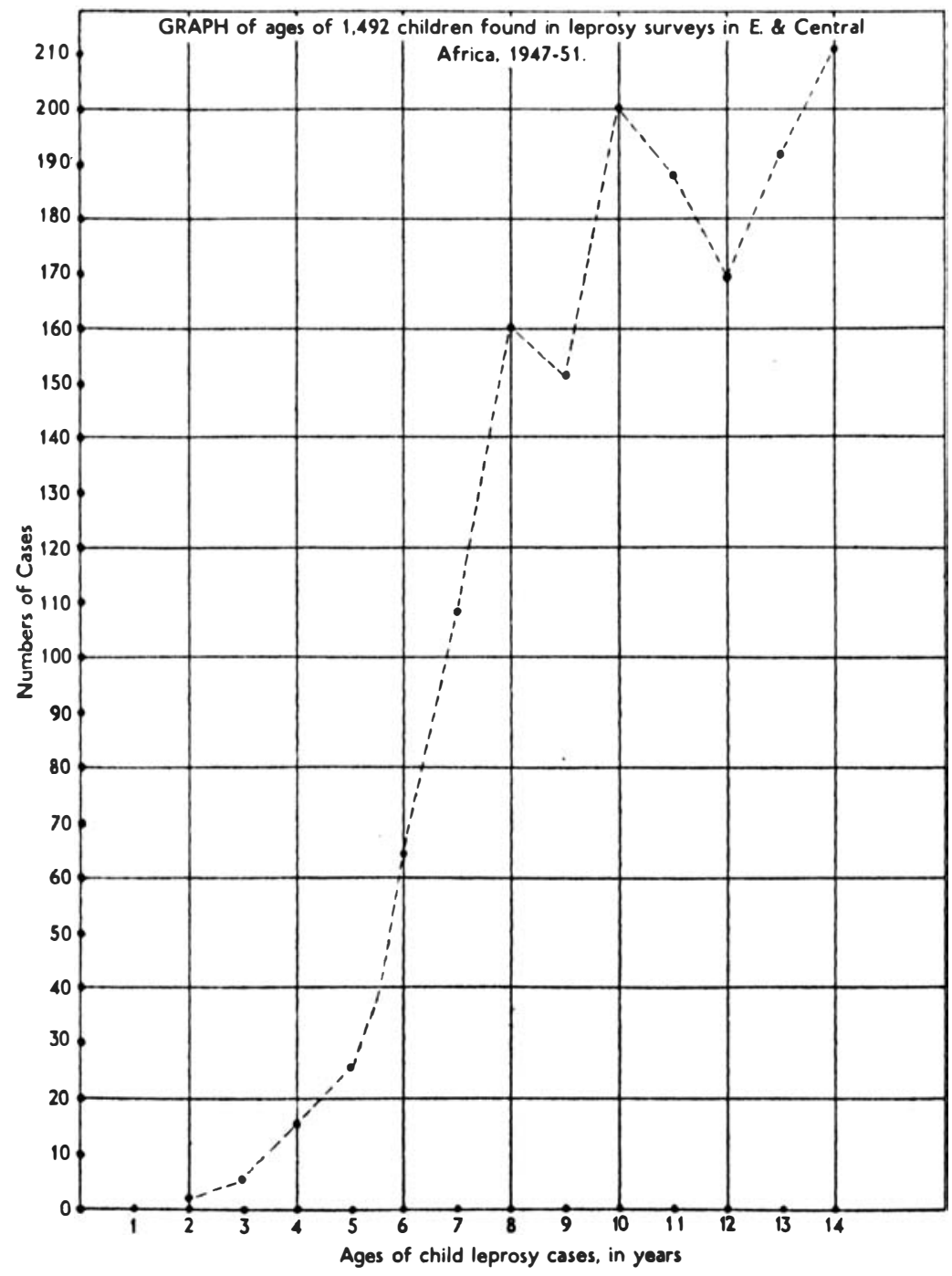


SECTION 4. The clinical type of the child leprosy.

Using the Havana Classification of Leprosy (1948) Ref. 19, it is proposed now to compare the cliniçal types of all the cases of leprosy with the clinical types in the children, as in the following table.

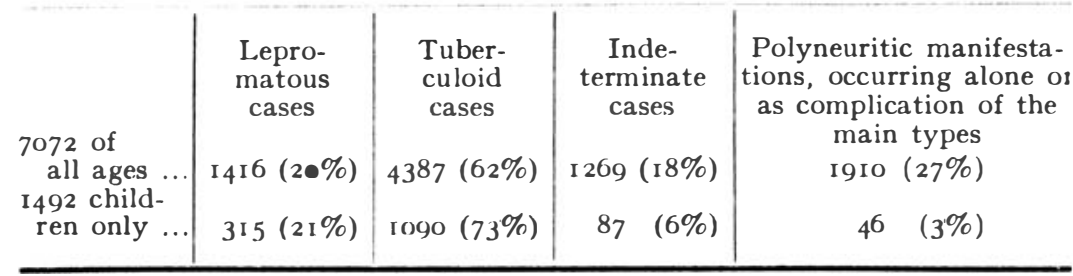

Comparing the two pictures, it will be seen that ...

(a) there is little difference in the lepromatous rate between children and the whole;

(b) tuberculoid cases in children are somewhat greater in number;

(c) indeterminate cases in children are few; in African children this poised state seems to be left to be experienced only when childhood is passed, and the child's leprosy career seems to begin either as a frank tuberculoid or a frank lepromatous manifestation;

(d) polyneuritic lesions, whether alone or complicating the main types, are very considerably less in these children; such lesions in their more obvious forms also seem to constitute an experience reserved for later career in leprosy; such polyneuritic lesions as were noted in these children were all at ages ro to I4 years.

\section{SECTION 5. How did the children acquire their leprosy?}

It is best to divide this question into three parts, namely where? from whom? and, under what conditions of living? (a) Where? Did they acquire it in the field, in the market-place, in travel, by one contact or a few momentary contacts? The answer is decidedly in the negative. There was not one case where this sort of infecting contact could be incriminated.

Did they acquire it in the process of living in a house or under some roof, where they were brought into daily, and more especially, nightly contact with others? The answer was found to be very clearly in the affirmative.

(b) From whom? The existence of an original infecting case has been shown in the great majority. Even in the apparent absence of any news of such a case, it was found that more enquiries would turn one up, sooner or later. 
Analysing the sources found, the infecting case or cases were adult in 93 per cent. of instances, and another child in only 7 per cent. Of the adult infectors, 67 per cent. were parents, and 33 per cent. were more or less close relatives, or family " hangers-on."

Instances of family groups of leprosy were common, ranging from the extreme example of mother and four children, to that of parent and one child, or uncle or aunt and one child.

Looking at the situation from the other side, in the general surveys it was found that only 5 per cent. of all leprosy cases genuinely lived alone, i.e., segregated. Of the rest, the average was three children living in home contact with each adult case of leprosy.

(c) Under what living conditions?

The living conditions of the children presented certain invariable features, namely . . .

overcrowding, or too many people inside the hut at night in relation to the cubic space;

darkness, by day, inside the dwelling;

bumidity, because in ill-ventilated crowded huts the vapour pressure rises and remains high, especially at night;

dietetic errors and deficiencies were a very common background to living in the case of these children; a great lack of first class biological protein is the commonest fault in diet;

debilitating diseases in a vast selection dogged most of these children, which diseases must have paved the way to the sustaining of leprosy infection; examples are hookworm, yaws, nutritional anaemias.

chronic skin diseases, such as are associated with scratching and breaches of the body surface, may have provided local portals of entry for the leprosy germ; examples are chronic scabies and the ringworms;

deficient badily cleanliness and clothes cleanliness was very common, and must also play some part in the acquisition of leprosy.

The living conditions above listed are commonly recognised to have relation to leprosy. Spacious and well-lighted houses, correct and adequate food, hygiene and cleanliness, and freedom from the load of debilitating diseases, would go a long way to prevent the passage of leprosy, even to the ever-susceptible young.

SECTION 6. These children having acquired leprosy, what is their fate?

In the first place, the existence of evanescent leprosy must be recognised in children. Thus Cochrane (I947) Ref. 20, describes 249 children under observation without treatment for 7 years, in whom about 62 cases had disappearance of all lesions of leprosy. 
Rodriguez (I926) Ref. 2I, pointed out also the evanescent nature of some lesions of children. MuIR (I936) Ref. 22, confirmed this by observations over many years. There is therefore little doubt that of all the children seen in the African leprosy surveys under present review, some have evanescent lesions subject to self-cure. The proportion can only be estimated, and the author's assessment is that one sixteenth of the total number might come under this category.

This should not blind us to the hard fact that a very great proportion of the children are destined to progress in their leprosy, and in the absence of remedial intervention, are doomed to become adult cases and the infectors of others in course of time. It cannot be forgotten that very many of these child cases were established cases of leprosy when first seen, out of the reach of any possible factor of evanescence. Such were, for example, the 3I5 lepromatous cases noted in the table in Section 4, or the 46 polyneuritic cases, or nearly $\mathrm{I}, 000$ of the tuberculoid and indeterminate cases.

It should be recalled that in the modern therapy of leprosy, children are especially responsive, and that a high rate of arrest of the disease can be expected in them. The problem resolves itself into the bringing of all child cases of leprosy under observation and care, and that again resolves itself into the determination and financial ability of the country in which they occur.

So far, in East and Central Africa, there is not enough accommodation and care available for all the cases of leprosy which exist, and in the default of same, one suggests that a concentration on child leprosy would be an economic step, one of the most rewarding of the many attacks that could be made on the leprosy problem. Hand in hand with special attention to lepromatous leprosy at all ages, if one at all times "went after " the children, control and eradication of the disease would be in sight.

SUMMARY.

By a study of data obtained in extensive leprosy surveys in East and Central Africa, I947-I95I, in which I,492 cases of child leprosy were found, certain facts and inferences have emerged . . .

I. A child case rate of $2 \mathrm{I} \%$ was found, and is taken to mean that leprosy is a living and growing entity in these countries.

2. The sex incidence was found to be $4: 3$, with males preponderating, and the suggestion is made that this may be due to females having more vital endowment, and being cleaner.

3. The age incidence of the child leprosy is recorded in a table 
and graph, and it is pointed out that between 5 and I4 years there is a great inrush of cases, and that a great proportion must have sustained their infection at a tender age, and that, generally speaking, leprosy is acquired in childhood and youth. It is inferred that leprosy is mainly a problem based in the environment and living conditions of children and the young.

4. The clinical types of the child leprosy are recorded in a table making also comparison with the leprosy at all ages. The relative infrequency emerges of indeterminate and polyneuritic types in African children.

5. How the children acquired their leprosy is recorded. For the most part, it was by living in poor hygienic conditions in contact with adult cases of leprosy. The importance of protection of children from leprosy infection is indicated as an important key to the abolition of leprosy from a people.

6. The fate of the children who acquired leprosy is discussed. In spite of the existence of evanescent leprosy of childhood, a great proportion of the children would progress in their leprosy and become infectors of others. The lack of adequate accommodation in these countries for all existing cases of leprosy is indicated, but special attention to children is recommended as one of the most economic and fruitful forms of attack on the leprosy problem.

\section{LIST OF REFERENCES.}

1. Innes, J. R., Leprosy in Uganda. East African Med. J. 25 (1948), 379. 381 .

2. Ibid. Leprosy in Kenya. Ibid. 26 (1949), 32-35.

3. Ibid. Leprosy in Tanganyika. Ibid. 26 (1949), 202-203.

4. Ibid. Leprosy in Tanganyika, Lake Prov. Ibid. 26 (1949), 199-201.

5. Ibid. Leprosy in Tanganyika, S. Highlands Province. Ibid. 26 (1949). 212-215.

6. Ibid. Leprosy and Leprosy Work in East Africa. Internat. J. of Leprosy. 18 (1950), 359-368.

7. Ibid. Leprosy in Uganda, Bugosa District. Ibid. 18 (1950), 507-517.

8. Ibid. Leprosy in Uganda, Kigezi District. East African Med. J., 27 (1950), 1-5.

9. Ibid. Leprosy in Tanganyika, S. Province. Ibid. 27 (1950), 459-465

10. Ibid. Leprosy in Northern Rhodesia. Ibid. 28 (1951), 21-28.

11. Ibid. Leprosy in Nyasaland. Ibid. 28 (1951), 168-173.

12. Ibid. Leprosy in Zanzibar and Pemba. Leprosy Review, 23 (1952), 459. 465.

13. Whfate, H. W., Leprosy in Teso Dist. of Uganda. East African Med. J., 28 (1951), 420-422.

14. Lowe, J., Sex Incidence in Leprory. Internat. J. of Leprosy, 2 (1934), 58.

15. Cochirane, R. G., Practical Textbouk of Leprosy. (1947), 19. 
16. De Souza Campos, N., and Df Souza Lima, L., Lepra na Infrancia. Monograph of Serviço Nacional de Lepra Rio de Janeiro, 1950; Reviewed in Internat. J. of Leprosy, 20 (1952) 314-315.

17. Lowe, J., Preliminary report of an epidemiological survey in a typical rural area of Bengal. Leprosy in India, 10 (1938), 41.

18. Cochrane. R. G., Practical Textbook of Leprosy. (1947), 12.

19. Memoria del V Congreso Internacional de la Lepra (official publication of the Government of Cuba). (1949) 481.487.

20. Cochrane, R. G., Practical Textbook of Leprosy. (1947), 12.

21. Rodriguez, J., Early Lesions in Children. Philippine J. of Science, 31 (1936), 115.

22. Muir, E., Juvenile Leprosy. Internat. J. of Leprosy, 4 (1936), 45. 